\title{
Effects of water-borne gametes on the aggregation behavior of Lytechinus variegatus
}

\author{
Daniel A. McCarthy ${ }^{1,2, *}$, Craig M. Young ${ }^{1}$ \\ ${ }^{1}$ Department of Larval Ecology, Harbor Branch Oceanographic Institute, 5600 North, Fort Pierce, Florida 34946, USA \\ ${ }^{2}$ Present address: Department of Biology and Marine Science, Jacksonville University, 2800 University Blvd. N, \\ Jacksonville, Florida 32211, USA
}

\begin{abstract}
Water-borne gametes are known to cue mass spawning in externally fertilizing marine invertebrates. In motile animals, such as sea urchins, they might also cue behavior to enhance fertilization success by either (1) increasing movement and thus the number of intraspecific encounters for numerous small-scale events or (2) causing the formation of small-sized aggregations for single spawning events. This study investigated the ability of water-borne gametes to induce spawning and aggregation behavior in the echinoid Lytechinus variegatus. In the field, 1 individual from each of 40 pairs of urchins was induced to spawn to test whether spawning would be induced in the other urchin. Additionally, 5 urchins were induced to spawn upstream from 20 individuals placed in a group. Thirteen replicates of this experiment were conducted to test whether the larger volume of gametes combined with more urchins would induce spawning. Ripe and nonripe urchins were also videotaped in a $2 \mathrm{~m}$ diameter pool with and without sperm in the water $(\mathrm{n}=3)$. All urchins were found to move rapidly $\left(50 \mathrm{~cm} \mathrm{~min}^{-1}\right)$, although the amount of movement, distance apart, and number and duration of encounters was the same regardless of their reproductive status or the presence/absence of sperm in the water. Urchins never spawned in response to water-borne gametes although most were found to be ripe.
\end{abstract}

KEY WORDS: Lytechinus variegatus $\cdot$ Movement $\cdot$ Behavior $\cdot$ Spawning $\cdot$ Aggregations $\cdot$ Echinoid

\section{INTRODUCTION}

In free-spawning marine invertebrates, synchronization of gamete release is necessary to enhance fertilization success. If gametes are shed asynchronously, they could lose viability and/or become too dilute for successful fertilization (Pennington 1985, Levitan et al. 1992, Sewell \& Levitan 1992, Levitan 1995). Phytoplankton (Smith \& Strehlow 1983, Starr et al. 1990, 1992), water temperature (Minchin 1992, Selvakumaraswamy \& Byrne 2000), day length (Minchin 1992, Selvakumaraswamy \& Byrne 2000) and waterborne gametes have been shown to cue spawning (Beach et al. 1975, Miller 1989, Unger \& Lott 1994, Hardege \& Bentley 1997). These stimuli presumably result in mass spawning which should enhance fertilization success if conspecifics are in close proximity (Levitan 1995).
Quantitative observations of mass spawning events by motile marine invertebrates are relatively rare and generally observed with temperate species. Several temperate species of echinoids (Minchin 1992, D. R. Levitan pers. comm.), crinoids (Meyer et al. 1984), seastars (Minchin 1987, Run et al. 1988) and holothurians (McEuen 1988, Sewell \& Levitan 1992) have been observed to mass spawn. In contrast, observations of spawning in tropical species have mostly been with animals living on the Great Barrier Reef (Babcock \& Mundy 1992, Babcock et al. 1992, Olsen et al. 1993). In most of these studies, only a few individuals of a species were observed to spawn at any one time (Pearse et al. 1988, Minchin 1992, Babcock et al. 1992, Olsen et al. 1993). Research on seasonal aggregations of some echinoderms also suggests that discrete spawning events can occur among individuals of subgroups of a population. Several species of temperate or deep-sea 
echinoderms have been observed to form aggregations during the reproductive season (Tyler et al. 1992, Young et al. 1992, Unger \& Lott 1994). Members of the aggregations were always more ripe than solitary individuals in the same population. Natural spawning was not observed in any of these studies, so it was unknown whether individuals in the aggregations spawned once or several times before they separated from their partner.

Some tropical species may spawn numerous times during intraspecific encounters that occur in their reproductive season. Populations of the echinoid $L y$ techinus variegatus reproduce from February through June and again from October through November off SE Florida (McCarthy \& Young 2002). Reproductive periods are characterized by females that are all ripe yet have different egg size distributions. This observation suggests that asynchronous spawning occurs within the population (McCarthy \& Young 2002). High (1 to $3 \mathrm{~m} \mathrm{~d}^{-1}$ ) urchin movement is likely to result in numerous intraspecific encounters during a single reproductive season. Such encounters may facilitate small-scale spawning events involving numerous individuals of the population. It is unknown whether cues that result in mass spawning by some species affect gamete release or reproductive behavior of species such as L. variegatus that spawn numerous times during a reproductive season.

This study investigated the role of water-borne gametes as cues for spawning and reproductive behavior in the echinoid Lytechinus variegatus. Field experiments tested (1) whether urchins in naturally occurring aggregations were more ripe than solitary urchins and (2) whether spawning in response to water-borne gametes is affected by aggregation size. Laboratory experiments tested whether ripe and nonripe urchins respond to sperm by (1) spawning, (2) moving faster to increase intraspecific encounters or (3) aggregating.

\section{MATERIALS AND METHODS}

Study areas. Field experiments were conducted in May 1994 with Lytechinus variegatus (55 to $65 \mathrm{~mm}$ in diameter) found off the SE shore of Virginia Key in Biscayne Bay, Florida (Fig. 1). Urchins collected from this area were also used for laboratory experiments during March and July 1994. Additional replicates of the field experiments were run in May 2002 with similar-sized L. variegatus found in the Intracoastal Waterway near Jupiter Inlet, Florida (Fig. 1). The bottom at both locations was level, ca. $1.5 \mathrm{~m}$ deep and covered homogeneously by a mixture of the seagrasses Thalassia testudinium, Syringodium filiforme and Halodule wrightii.

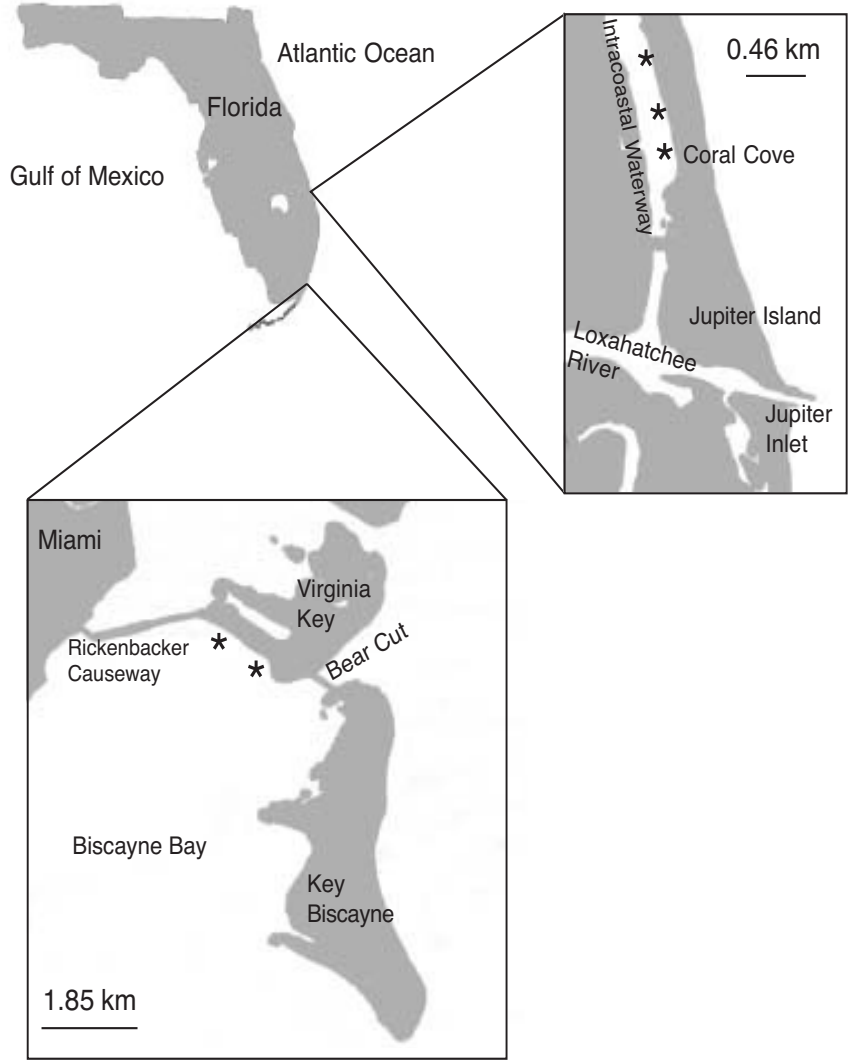

Fig. 1. Study areas in Florida. Bottom panel shows close up of Key Biscayne area. Right panel shows close up of Jupiter area. *: specific study sites within each area

Aggregation as a function of reproductive state. To test whether ripe urchins were more likely to be aggregated or solitary, the proportion of reproductive individuals in naturally occurring pairs was compared with randomly paired solitary urchins. Twenty pairs and 40 solitary urchins were sampled in 1994 in Virginia Key and again in 2002 at Jupiter inlet. Aggregated urchins consisted of at least 2 individuals with their spines touching. Solitary urchins were at least $2 \mathrm{~m}$ from any conspecific. Sex and gonad maturity were determined by either histological examination of gonads or injection of $0.55 \mathrm{M} \mathrm{KCL}$ to induce spawning. For each location, a $G$-test was used to compare the likelihood that randomly paired and observed pairs will have 0, 1 or 2 reproductive individuals (Sokal \& Rohlf 1995). A Kruskal-Wallis test was used to determine where the number of urchins in each category varied between 1994 and 2002 (Sokal \& Rohlf 1995)

Spawning responses of natural and artificial aggregations. In the field, 1 individual from each of 40 naturally occurring pairs of urchins was induced to spawn with $0.55 \mathrm{M} \mathrm{KCl}$ to test whether the presence 
of gametes would induce spawning in the other urchin of the pair (see Fig. 2). Ten urchin pairs were tested at Virginia Key in 1994 with an additional 30 pairs tested at Jupiter Inlet in 2002. In a second set of experiments, 5 urchins were placed $0.25 \mathrm{~m}$ upstream from a group of 20 individuals. The upstream group was injected with $0.55 \mathrm{M} \mathrm{KCl}$ to test whether gametes drifting down over the downstream group would induce any of these individuals to spawn. In these experiments, a $15 \mathrm{~min}$ acclimation time period was allowed prior to each run to minimize any behavioral artifacts from handling. Normally, urchins would quickly stop moving if they were in an area with some seagrass cover. In both experiments, urchins were observed for $30 \mathrm{~min}$ after the induction of spawning. Three runs were done at Virginia Key in 1994 and 10 at Jupiter Inlet in 2002.

Movement and aggregation responses to sperm. This experiment tested whether ripe and nonripe urchins responded to the presence of sperm by (1) spawning, (2) moving fast to increase intraspecific encounter rates or (3) remaining aggregated when encounters occurred. Three replicate samples of 9 urchins were videotaped indoors in a $2 \mathrm{~m}$ diameter fiberglass tank (20 cm depth) with no outside circulation for $6 \mathrm{~h}$ periods using a video camera wired to a time-lapse VCR (see Fig. 3). Water temperature, dissolved oxygen and salinity were monitored during all runs. The first $6 \mathrm{~h}$ run started in the early morning. Urchins were initially placed approximately $0.25 \mathrm{~m}$ apart. At the end of the first run of each day, the pool was drained, cleaned and the urchins were rinsed with clean seawater. They were then placed back into the newly filled pool for the second run. Sperm from 8 additional male urchins obtained by $\mathrm{KCl}$ injection were combined with seawater in a $1000 \mathrm{ml}$ container to create a highly concentrated solution of fresh sperm. The solution was added to the pool at the beginning of the run and a fresh sperm suspension was added $3 \mathrm{~h}$ later. During successive days of the experiment, the order of the sperm treatment and the non-sperm treatment was alternated to block for potential artifactual differences between the morning and afternoon. Three replicates of these experiments were completed during March (reproductive season) and July (nonreproductive period) to investigate potential seasonal behavioral differences.

The videotape data were analyzed on a video monitor by tracing the path of each urchin and recording (1) the distance traveled for each hour of the experiment, (2) the mean distance from each urchin to its nearest neighbor and (3) the number of encounters and duration of each encounter during the course of the experiment. Each of these data sets was analyzed with a 2-factor (reproductive state, sperm in the water) repeated measures (each successive hour) ANOVA (SYSTAT 1992).

\section{RESULTS}

\section{Aggregation as a function of reproductive state}

A G-test revealed no significant difference in the proportion of reproductive individuals between naturally occurring pairs and single individuals paired at random (Fig. 2). In 1994, there were 8 male/male, 5 male/female, 3 female/female, 3 male nonripe and 1 nonripe/nonripe combinations (Fig. 2a). There were 20 male, 15 female and 5 nonripe solitary urchins. In 2002, there were 4 male/male, 14 male/ female and 2 female/female combinations (Fig. 2b). In this year, there were 23 male, 15 female and 2 nonripe solitary urchins. The number of urchin pairs in each of the 3 categories $(0,1$ or 2 ripe individuals) did not vary significantly between 1994 and 2002 (Kruskal-Wallis statistic $=0.5162, \mathrm{p}<0.915)$.
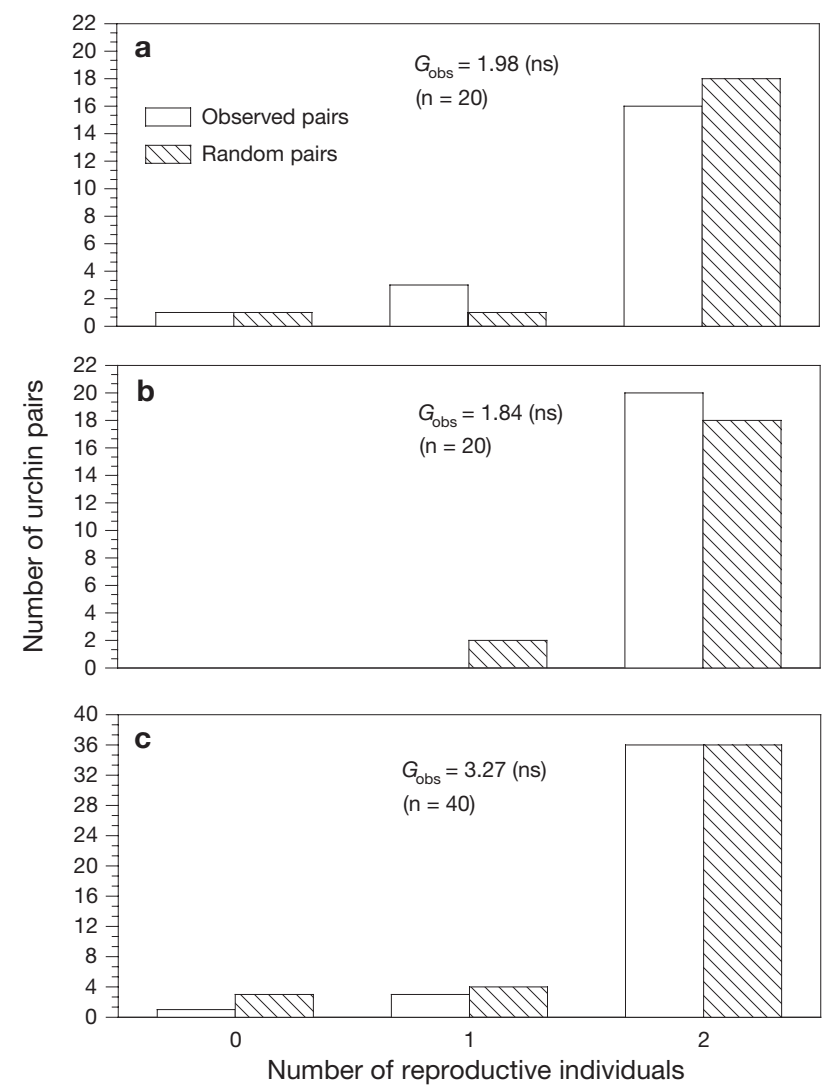

Fig. 2. Lytechinus variegatus. Number of observed versus randomly paired sea urchins having 0,1 or 2 reproductive individuals in (a) 1994, (b) 2002 and (c) the 2 yr combined. $G_{\text {obs }}=$ observed $G$ value. ns = not significant 


\section{Spawning responses in natural and artificial aggregations}

No individual in any of the 40 naturally occurring pairs spawned when its partner was induced to spawn with $0.55 \mathrm{M} \mathrm{KCl}$ (Fig. 3). In 1994, there were 5 all male and 1 all female pairs of urchins (Fig. 3a). There was 1 pair of nonripe urchins and 3 pairs with nonripe partners. In the latter case, all ripe individuals were females. In 2002, all individuals in the 30 encountered pairs were ripe (Fig. 3b). In $60 \%$ of the pairs in the experiment, $\mathrm{KCl}$ injection resulted in a male spawning next to a non-spawning female. A male spawning next to a non-spawning male was encountered $20 \%$ of the time, while a female to a male or a female accounted for the remaining $20 \%$ of the experimental pairs.

In the 13 artificial aggregates, only 1 female spawned in response to injected individuals that were spawning. Within each group (a total of 260 ) $90 \%$ of all individuals were ripe with $10 \%$ being nonreproductive. The sex ratios for the upstream and downstream groups appeared similar for 1994 and 2002 (Fig. 4).
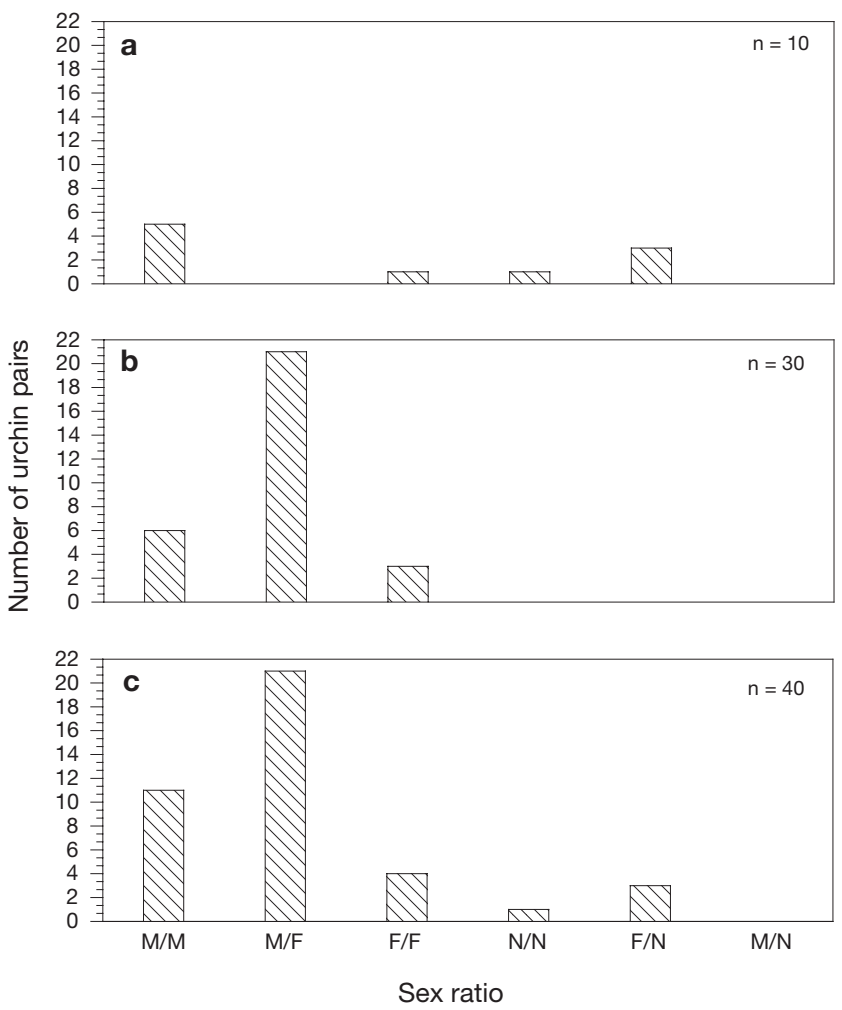

Fig. 3. Lytechinus variegatus. Sex ratio of observed pairs of sea urchins used in field spawning experiments in (a) 1994, (b) 2002 and (c) the 2 yr combined. No individual in any of the pairs spawned when its partner was induced to spawn. $\mathrm{M}=$ male; $\mathrm{F}=$ female $; \mathrm{N}=$ nonripe

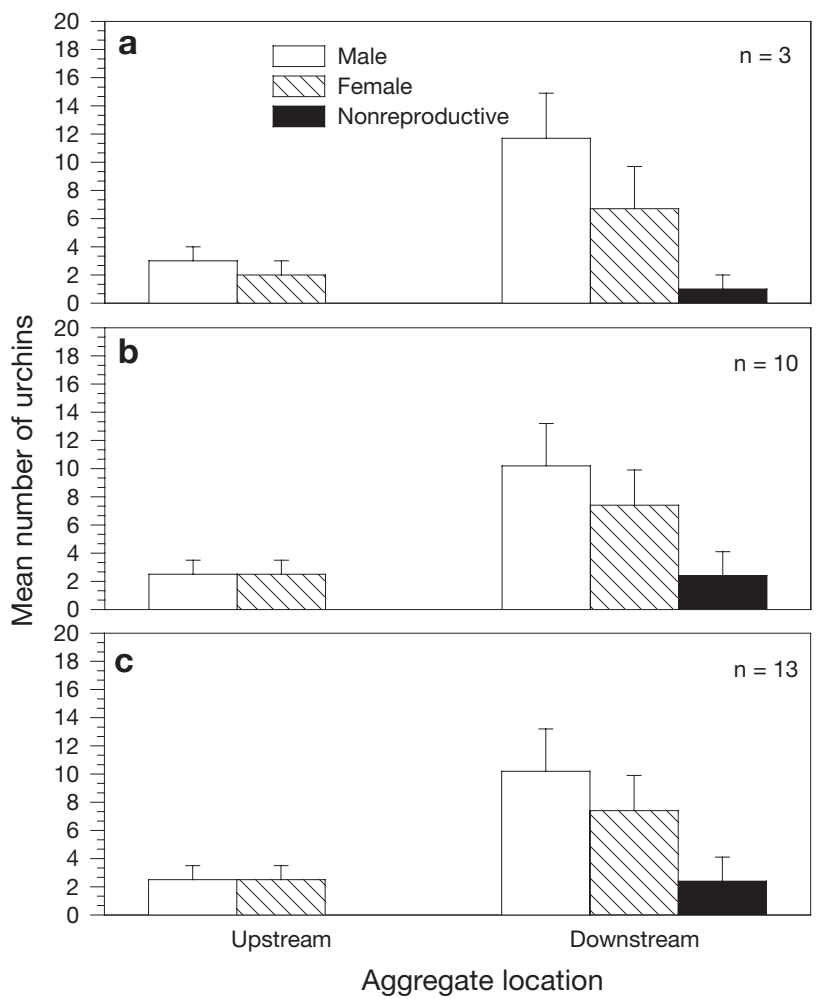

Fig. 4. Lytechinus variegatus. Mean number (+SD) of urchins of each sex in upstream $(\mathrm{n}=5)$ and downstream $(\mathrm{n}=20)$ groups in (a) 1994, (b) 2002 and (c) the 2 yr averaged

\section{Movement and aggregation responses to water-borne gametes}

No spawning was observed by any of the urchins during the laboratory experiments. Histological sections of gonads revealed that, during the nonreproductive season, $100 \%$ of the urchins had gonads that were in early gametogenesis. During the reproductive season, $92 \%$ of the urchins were ripe, with $8 \%$ being in earlier gametogenic stages. Urchin behavior was not observed to be different between ripe and nonripe individuals during the reproductive season.

The mean distance traveled during each hour of the laboratory experiment averaged between 25 and $175 \mathrm{~cm}$ (Fig. 5). No significant difference was found between any treatment means although the mean locomotory rate was lowest for fully ripe urchins with sperm in the water than any of the other treatments (Table 1, Fig. 5). A significant time effect (logtransformed data) was found $(F=8.79 ; \mathrm{p}<0.001)$ in which the mean locomotory rate was fastest in the first hour of the $6 \mathrm{~h}$ experiment (Table 1).

The mean distance between urchins varied from 26 to $42 \mathrm{~cm}$ (Fig. 6). No significant differences were found among treatment means. However, generally the mean 


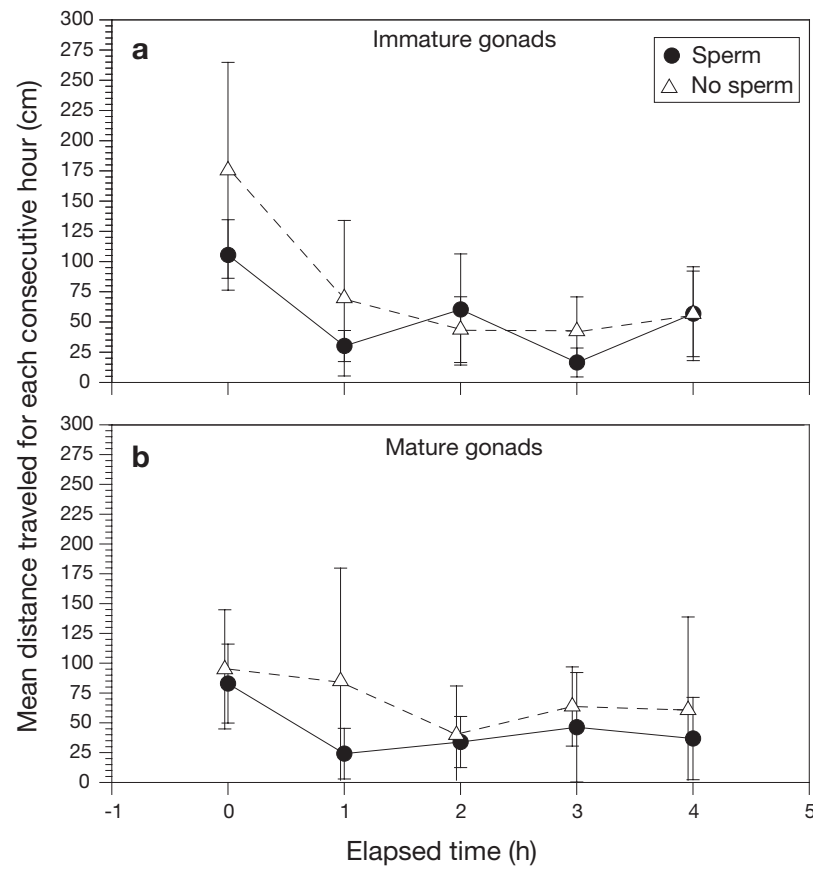

Fig. 5. Lytechnius variegatus. Hourly mean distance traveled ( $\pm 1.0 \mathrm{SD}$ ) by urchins with (a) immature and (b) mature gonads in treatments with and without sperm. There was an overall significant time effect $(\mathrm{p}<0.001)$

distance between ripe urchins in the treatment with sperm was lower than the other treatments (Table 2).

The duration of intraspecific encounters varied from seconds to nearly 80 min (Fig. 7). There were no significant differences in the mean number of encounters

Table 1. Lytechinus variegatus. Results of 2-way repeated measures ANOVA comparing distance traveled by ripe and nonripe urchins. Independent factors are reproductive state; Rs (2 levels) and the presence or absence of sperm. Means of distance traveled were log-transformed in order to meet assumptions of ANOVA

\begin{tabular}{|lrrrrc|}
\hline Source & $\mathrm{SS}$ & $\mathrm{df}$ & $\mathrm{MS}$ & F-ratio & $\mathrm{p}$ \\
\hline Between subjects & & & & & \\
$\quad$ Reproductive & 1398.2 & 1 & 1398.2 & 0.200 & 0.666 \\
state (Rs) & 8017.1 & 1 & 8017.1 & 1.148 & 0.315 \\
Sperm & 5.7 & 1 & 5.7 & 0.001 & 0.978 \\
Rs $\times$ Sperm & 55857.2 & 8 & 6982.1 & & \\
Error & & & & & \\
Within subjects & 43890 & 4 & 10972.4 & 9.9 & 0.001 \\
Time & 9706 & 4 & 2426.6 & 2.2 & 0.119 \\
Time $\times$ Rs & 6041 & 4 & 1104 & 0.844 & 0.278 \\
Time $\times$ Sperm & 3728 & 4 & 932 & 1.368 & 0.478 \\
Time $\times$ Rs $\times$ Sperm & 35328 & 32 & 1104 & & \\
Error & & & & & \\
\hline
\end{tabular}

among treatment means (Table 3a). The longest duration of encounters occurred in the treatment with ripe urchins and sperm present although it was not found to be significant (Table $3 b$ ).

Environmental factors were at fairly consistent levels for experimental runs within each season (reproductive or nonreproductive) of 1994 (Table 4). Most measurements were also fairly similar between runs of both seasons (Table 4). Water temperature was the exception, with values of $24.8^{\circ} \mathrm{C}$ and $29.0^{\circ} \mathrm{C}$ for March and July, respectively. We ran several Pearson correlations to determine whether changes in environmental factors during the course of the day may have affected the experimental results. No significant correlations could be found between any of the measured environmental factors and dependent variables.

\section{DISCUSSION}

\section{Aggregation as a function of reproductive state}

Ripe Lytechinus variegatus were found alone and also in small aggregations at both Virginia Key and Jupiter Inlet. This suggests that ripe individuals (1) might not be able to find each other easily, (2) randomly find each other and stay together either seasonally or for a short time, (3) are waiting to respond to a localized cue to temporarily aggregate or (4) do not aggregate for reproduction. It appears that $L$. variegatus does not seasonally aggregate as previously investigated (McCarthy \& Young 2002). Therefore, if small-scale reproductive aggregations occur, they must be short term and result from either random encounters or a very localized cue.

\section{Spawning responses in natural and artificial aggregations}

Gametes spawned over natural and artificial aggregations failed to cue spawning from most members at both locations. At Virginia Key, some nonripe urchins were encountered in collected pairs whereas all pairs were ripe at Jupiter Inlet. The sex ratio and number of ripe individuals of upstream and downstream groups of urchins was similar at both sites. No differences in response could be related to the size of the aggregation. These results could have occurred because (1) of chemical interference by $\mathrm{KCl}_{\text {, (2) natural re- }}$ 


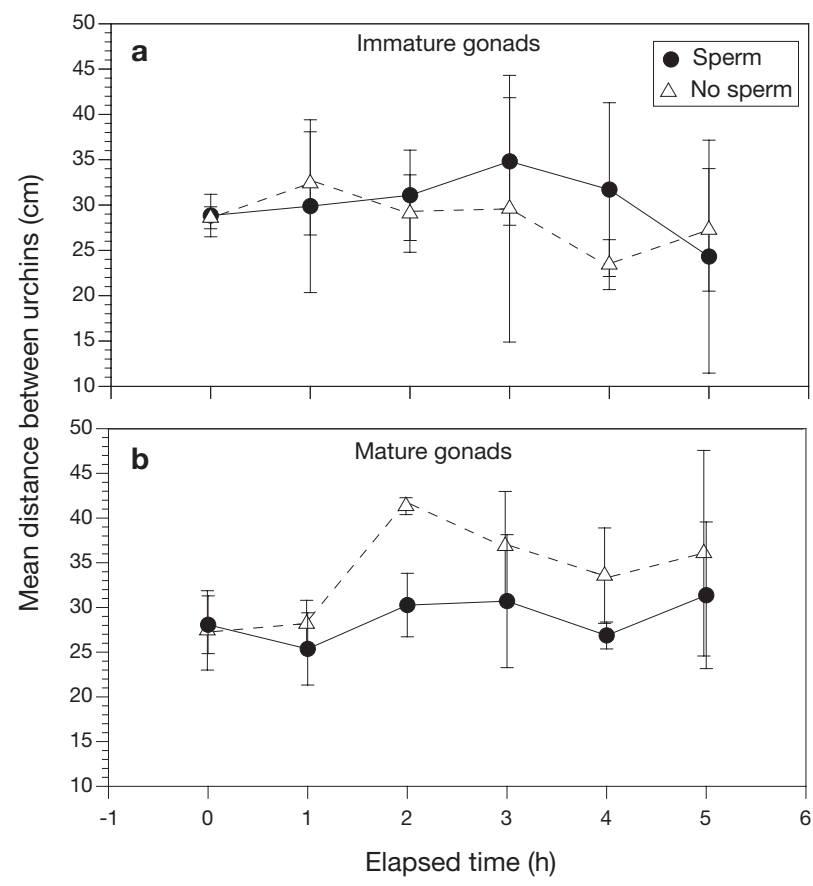

Fig. 6. Lytechinus variegatus. Hourly mean $( \pm 1.0 \mathrm{SD})$ distance between urchins with (a) immature and (b) mature gonads in treatments with and without sperm. No significant differences were found among the treatment means

sponses were obscured by urchin reactions to handling or (3) urchins were not given enough time to respond. However, others have obtained positive results using similar techniques.

Unger \& Lott (1994) were able to use water-borne gametes to induce spawning by Sphaerechinus granu-

Table 2. Lytechinus variegatus. Results of 2-way repeated measures ANOVA comparing mean distance between urchins. Independent factors are reproductive state. Rs (2 levels) and the presence or absence of sperm

\begin{tabular}{|lrrrrc|}
\hline Source & \multicolumn{1}{c}{ SS } & df & MS & F-ratio & p \\
\hline Between subjects & & & & & \\
$\quad$ Reproductive & & & & & \\
$\quad$ state (Rs) & 73.8 & 1 & 73.8 & 0.730 & 0.418 \\
Sperm & 48.1 & 1 & 48.1 & 0.477 & 0.510 \\
Rs $\times$ Sperm & 196.4 & 1 & 196.4 & 1.942 & 0.201 \\
Error & 808.9 & 8 & 101.1 & & \\
Within subjects & & & & & \\
Time & 280.0 & 5 & 56.0 & 1.5 & 0.207 \\
Time $\times$ Rs & 305.0 & 5 & 60.8 & 1.64 & 0.171 \\
Time $\times$ Sperm & 78.0 & 5 & 15.7 & 0.42 & 0.829 \\
Time $\times$ Rs $\times$ Sperm & 182.0 & 5 & 36.4 & 0.98 & 0.441 \\
Error & 1480.0 & 40 & 37.0 & & \\
\hline
\end{tabular}

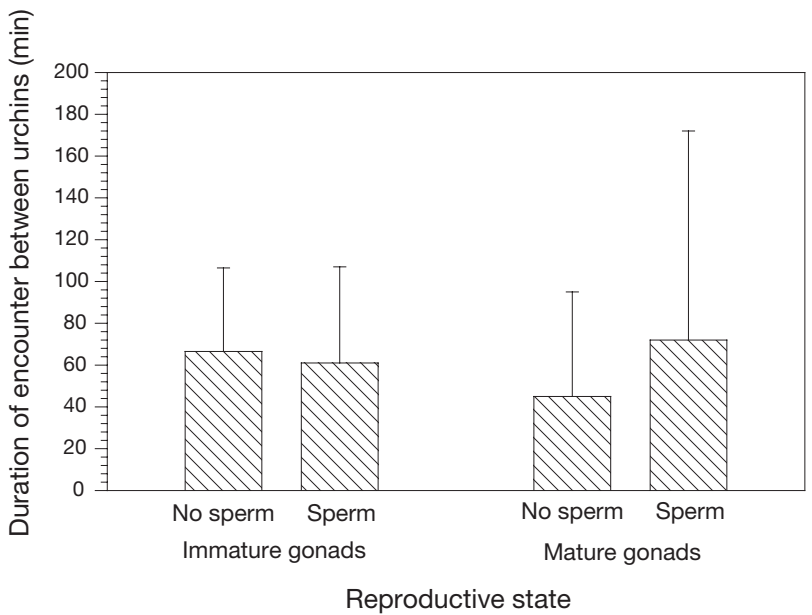

Fig. 7. Lytechinus variegatus. Mean duration of encounters $(+1.0 \mathrm{SD})$ in the laboratory experiment with ripe and nonripe urchins, in the presence and absence of sperm. No significant differences were found among the treatment means

laris found in natural aggregations. Urchins were given a short acclimation, yet still spawned in response to water-borne gametes within $20 \mathrm{~min}$ of the start of the experiment.

We believe that if water-borne gametes induce spawning or behavior in Lytechinus variegatus, they do so in combination with 1 or several exogenous factors that did not exist in our experiments. For instance, water-borne gametes may only be important when present with phytoplankton, moon phase, tide or darkness. It is has been suggested that L. variegatus spawning may be linked to the lunar phase (Moore et al. 1963, Moore \& Lopez 1972, Lessios 1991, Watts et al. 2001) and that they are more active during the night (P. Kier pers. comm.). If we had conducted our experiments during these times, perhaps we may have observed behavioral responses from the urchins cued by water-borne gametes.. However, if gametes do not work in synergy with some other factor such as moon phase or night, they may not be important at all in inducing spawning in L. variegatus. Gamete release may occur directly in response to any of the above-mentioned environmental factors. It may also result from a pheremone or tactile stimulus. Chemical communication has been implicated in initiating and maintaining synchronization of gametogenesis in the holothuroid Cucumaria frondosa (Hamel \& Mercier 1996). 
Table 3. Lytechinus variegatus. Results of 2-way ANOVA comparing (a) the number of encounters and (b) duration of encounters of urchins in the laboratory experiment. The independent factors are reproductive state; Rs (2 levels) and the presence or absence of sperm. Means of encounter duration time were logtransformed in order to meet assumptions of ANOVA

\begin{tabular}{|clccccc|}
\hline $\begin{array}{l}\text { Dependent } \\
\text { variable }\end{array}$ & Source & SS & df & MS & F-ratio & $\mathrm{p}$ \\
\hline $\begin{array}{c}\text { (a) Encounter } \\
\text { number }\end{array}$ & $\begin{array}{l}\text { Reproductive } \\
\text { state (Rs) }\end{array}$ & 12.0 & 1 & 12.0 & 0.364 & 0.563 \\
& Sperm & 40.3 & 1 & 40.3 & 1.222 & 0.301 \\
& Rs $\times$ Sperm & 56.3 & 1 & 56.3 & 1.707 & 0.228 \\
& Error & 264.0 & 8 & 33.0 & & \\
(b) Encounter & Reproductive & & & & & \\
duration & state (Rs) & 0.153 & 1 & 0.153 & 0.159 & 0.700 \\
& Sperm & 0.022 & 1 & 0.022 & 0.023 & 0.882 \\
& Rs $\times$ Sperm & 1.035 & 1 & 1.035 & 1.076 & 0.330 \\
& Error & 7.695 & 8 & 0.962 & & \\
\hline
\end{tabular}

\section{Movement and aggregation responses to sperm}

Sperm did not induce spawning, increase locomotory rates and change mean distance between urchins or change durations of encounters. Behavioral responses did not change with the reproductive state of the urchins nor did they appear related to any of the environmental factors measured in this experiment.

Individual Lytechinus variegatus were found to move at heightened speeds in what seemed to be random directions immediately after being handled. They then slowed down after $1 \mathrm{~h}$ and maintained much slower locomotory rates. It is likely that this is an evasion response to handling. Similarly, members of aggregations of the echinoid Diadema spp. quickly moved in a direction away from a perceived threat when 1 individual of the aggregate was touched (Pearse \& Arch 1969).

The lack of significant effects by the independent factors in these experiments could be because of any of the same reasons outlined for the field experiments.

Table 4. Dissolved oxygen, salinity and temperature means $( \pm 1.0 \mathrm{SD})$ for laboratory experiment with Lytechinus variegatus during March and July 1994

\begin{tabular}{|lrrrrrr|}
\hline & \multicolumn{2}{c}{ March 1994 } & & \multicolumn{2}{c|}{ July 1994 } \\
\cline { 2 - 3 } & Morning & Afternoon & & Morning & Afternoon \\
\hline Oxygen $\left(\mathrm{g} \mathrm{ml}^{-1}\right)$ & $5.6(0.45)$ & $5.2(0.94)$ & & $5.5(0.41)$ & $5.8(0.56)$ \\
Salinity (ppt) & $28.2(0.47)$ & $29.3(0.94)$ & & $29.0(0.13)$ & $29.2(0.24)$ \\
Water temp $\left({ }^{\circ} \mathrm{C}\right)$ & $28.3(0.61)$ & $29.4(0.42)$ & & $24.5(0.14)$ & $25.0(0.16)$ \\
\hline
\end{tabular}

However, unlike the field experiments, the presence of gametes in the water had more time $(6 \mathrm{~h})$ to induce a response. If urchins respond to waterborne gametes, $6 \mathrm{~h}$ is probably a reasonable time to expect a response. Otherwise, a spawning individual would waste an enormous number of gametes before successful reproduction could occur. Further, most $\mathrm{KCl}-$ induced Lytechinus variegatus only spawn for approximately 10 to $20 \mathrm{~min}$ (D. A. McCarthy unpubl. data).

Handling before and during the experiments may have adversely affected urchin behavior. It is possible that some of the urchins spawned a little during handling prior to the experiment. While urchins were generally ripe in our experiments, their gonads may not have been at peak capacity to spawn in response to gametes. Also, prior to each experimental run, the urchins may not have had a sufficient acclimation period with enough natural settings like sand/grass to completely stimulate them to respond as they would in their natural habitat.

\section{CONCLUSIONS}

Water-borne gametes do not appear to affect spawning or reproductive behavior in Lytechinus variegatus. If they do induce such responses, it is most likely that they do so synergistically with either (1) one or several other environmental factors or (2) localized cues from urchins such as pheremones and/or touch. Further, it is likely that such cues will only induce spawning and behavioral responses in small groups within a population. Asynchronous oocyte distributions among ripe females (Beddingfield \& McClintock 1998, 2000, McCarthy \& Young 2002) suggest urchins may sporadically spawn small cohorts of gametes numerous times during the reproductive season. Considering such a spawning method, a large number of $L$. variegatus might not be expected to simultaneously respond to water-borne gametes like some mass spawning temperate species. Reproductive responses in $L$. variegatus may only occur during very short time periods during the reproductive season, when several urchins are reproductively ready, and the appropriate endogenous or exogenous cues are present. 
Acknowledgements. We thank J. Richard and S. Reed for their assistance in the field. We thank D. Vaughan for providing the facilities for our laboratory experiments. We also thank E. Gonzales for helpful comments on the manuscript. This research was funded by the National Science Foundation (OCE-9116560) and is Harbor Branch contribution number 1559 and Smithsonian Marine Station at Fort Pierce contribution number 587.

\section{LITERATURE CITED}

Babcock RC, Mundy CN (1992) Reproductive biology, spawning and field fertilization rates of Acanthaster planci. Aust J Mar Freshw Res 43:525-534

Babcock RC, Mundy CN, Keesing J, Oliver J (1992) Predictable and unpredictable spawning events: in situ behavioural data from free-spawning coral reef invertebrates. Invertebr Reprod Dev 22:213-228

Beach DH, Hanscomb NJ, Ormond RFG (1975) Spawning pheromone in crown-of-thorns starfish. Nature 254: 135-136

Beddingfield SD, McClintock JB (1998) Differential survivorship, reproduction, growth and nutrient allocation in the regular echinoid Lytechinus variegatus (Lamark) fed natural diets. J Exp Mar Biol Ecol 226:195-215

Beddingfield SD, McClintock JB (2000) Demographic characteristics of Lytechinus variegatus (Echinoidea: Echinodermata) from three habitats in a North Florida Bay, Gulf of Mexico. PSZN I: Mar Ecol 21:17-40

Hamel JF, Mercier A (1996) Evidence of chemical communication during the gametogenesis of holothuroids. Ecology 77:1600-1616

Hardege JD, Bentley MG (1997) Spawning synchrony in Arenicola marina: evidence for sex phermonal control. Proc R Soc Lond Ser B 264(1394):1041-1047

Lessios HA (1991) Presence and absence of monthly reproductive rhythms among eight Caribbean echinoids off the coast of Panama. J Exp Mar Biol Ecol 153:27-47

Levitan DR (1995) The ecology of fertilization in freespawning invertebrates. In: McEdward L (ed) Ecology of marine invertebrate larvae. CRC Press, Boca Raton, FL, p 123-156

Levitan DR, Sewell MA, Chia F-S (1992) How distribution and abundance influence fertilization success in the sea urchin Strongylocentrotus franciscanus. Ecology 73: $248-254$

McCarthy DA, Young CM (2002) Gametogenesis and reproductive behavior in the echinoid Lytechinus variegatus. Mar Ecol Prog Ser 233:157-168

McEuen FS (1988) Spawning behaviors of northeast Pacific sea cucumbers (Holothuroidea: Echinodermata). Mar Biol 98:565-585

Meyer DL, Lahaye CA, Holland ND, Arneson AC, Strickler JR (1984) Time-lapse cinematography of feather stars (Echinodermata: Crinoidea). Mar Biol 78:179-184

Miller RL (1989) Evidence for the presence of sexual pheromones in free-spawning starfish. J Exp Mar Biol Ecol 130: 201-221

Minchin D (1987) Sea-water temperature and spawning behaviour in the seastar Marthasterias glacialis. Mar Biol 95:139-143

Minchin D (1992) Multiple species, mass spawning events in an Irish sea lough: the effect of temperatures on spawn-

Editorial responsibility: Kenneth Heck (Contributing Editor), Dauphin Island, Alabama, USA ing and recruitment of invertebrates. Invertebr Reprod $22: 1-3$

Moore HB, Lopez NN (1972) Factors controlling the seasonal spawning pattern of Lytechinus variegatus. Mar Biol 14: $275-280$

Moore HB, Jutare T, Bauer JC, Jones JA (1963) The biology of Lytechinus variegatus. Bull Mar Sci Gulf Carribb 13:23-53

Olsen RR, Cameron JL, Young CM (1993) Larval development (with observations on spawning) of the pencil urchin Phyllacanthus imperialis: a new intermediate larval form. Biol Bull (Wood Hole) 185:77-85

Pearse JS, Arch SW (1969) The aggregation behavior of Diadema (Echinodermata, Echinoidea). Micronesica 5: 165-171

Pearse JS, McClary DJ, Sewell MA, Austin WC, Perez-Ruzafa, Byrne M (1988) Short communication: Simultaneous spawning of six species of echinoderms in Barkley Sound British Columbia. Invertebr Reprod Dev 14:279-288

Pennington JT (1985) The ecology of fertilization of echinoid eggs: the consequences of sperm dilution, adult aggregation, and synchronous spawning. Biol Bull (Woods Hole) 169:417-430

Run JQ, Chen CP, Chang KH, Chia FS (1988) Mating behavior and reproductive cycle of Archaster typicus (Echinodermata: Asteroidea). Mar Biol 99:247-253

Selvakumaraswamy P, Bryne M (2000) Reproduction, spawning, and development of 5 ophiuroids from Australia and New Zealand. Invertebr Biol 119:394-402

Sewell MA, Levitan DR (1992) Fertilization success during a natural spawning of the dendrochirote sea cucumber Cucumaria miniata. Bull Mar Sci 51:161-166

Smith JR, Strehlow DR (1983) Algal-induced spawning in the marine mussel Mytilus californianus. Int J Invertebr Reprod 6:129-133

Sokal RR, Rohlf FJ (1995) Biometry: the principles and practice of statistics in biological research, 3rd edn. WH Freeman, New York

Starr M, Himmelman JH, Therriault JC (1990) Direct coupling of marine invertebrate spawning with phytoplankton blooms. Science 247:1071-1074

Starr M, Himmelman JH, Therriault JC (1992) Isolation and properties of a substance from the diatom Phaeodactylum tricornutum which induces spawning in the sea urchin Strongylocentrotus drobachiensis. Mar Ecol Prog Ser 79: 275-287

SYSTAT (1992) SYSTAT for Windows: Statistics, version 5 edn. Systat Software, Evanston, IL

Tyler PA, Young CM, Billett DSM, Giles LA (1992) Pairing behaviour, reproduction and diet in the deep-sea holothurian genus Paroriza (Holothurioidea: Synallactidae). J Mar Biol Assoc UK 72:447-462

Unger B, Lott C (1994) In-situ studies on the aggregation behaviour of the sea urchin Sphaerechinus granularis LAM. (Echinodermata: Echinoidea). In: David B, Guille A, Feral JP, Roux M (eds) Echinoderms through time. AA Balkema, p 913-919

Watts SA, McClintock JB, Lawrence JM (2001) The ecology of Lytechinus variegatus. In: Lawrence JL (ed) Edible sea urchins: Biology and ecology. Elsevier Science, Amsterdam, p 375-393

Young CM, Tyler PA, Cameron JL, Rumrill SG (1992) Seasonal breeding aggregations in low-density populations of the bathyal echinoid Stylocidaris lineata. Mar Biol 113: $603-612$

Submitted: December 5, 2002; Accepted: June 1, 2004

Proofs received from author(s): November 22, 2004 